\title{
TITLE:
}

\section{Around LTD hypothesis in motor learning.}

$\operatorname{AUTHOR}(S)$ :

Hirano, Tomoo

CITATION:

Hirano, Tomoo. Around LTD hypothesis in motor learning.. Cerebellum 2014, 13(5): 645-650

ISSUE DATE:

2014-06-29

URL:

http://hdl.handle.net/2433/201102

\section{RIGHT:}

The final publication is available at Springer via http://dx.doi.org/10.1007/s12311-0140581-4.; This is not the published version. Please cite only the published version.; この論 文は出版社版でありません。引用の際には出版社版をご確認ご利用ください。 


\title{
Around LTD Hypothesis in Motor Learning
}

\author{
Tomoo Hirano
}

Department of Biophysics, Graduate School of Science, Kyoto University,

Sakyo-ku, Kyoto 606-8502, Japan

E-mail: thirano@neurosci.biophys.kyoto-u.ac.jp

Tel: 81-75-753-4237, Fax: 81-75-753-4229

Key words

LTD, LTP, RP, Motor learning, Vestibulo-ocular reflex, Classical conditioning, Purkinje cell, Parallel fiber 


\section{Conflict of interest notification}

I declare no conflict of interest. 


\begin{abstract}
Long-term depression (LTD) at parallel fiber-Purkinje neuron synapses have been regarded as a primary cellular mechanism for motor learning. However, this hypothesis has been challenged. Demonstration of normal motor learning under LTD-suppressed conditions suggested that motor learning can occur without LTD. Synaptic plasticity mechanisms other than LTD have been found at various synapses in the cerebellum. Animals may achieve motor learning using several types of synaptic plasticity in the cerebellum including LTD.
\end{abstract}




\section{Introduction}

Marr and Albus, two theoreticians proposed that the efficacy of information transmission at a synapse between a parallel fiber $(\mathrm{PF})$ and a Purkinje neuron $(\mathrm{PN})$ in the cerebellar cortex changes depending on the activity of a climbing fiber (CF) [1, 2]. A PN receives an extraordinary large number of excitatory synaptic input from more than 100,000 PFs and a very strong input from only one CF, which seems to code an error signal (Figure 1). Albus considered that the PF-PN synaptic transmission that was active in a motor performance and ended in failure, is suppressed depending on the CF input. Then, Ito and colleagues reported that conjunctive activation of PFs and a CF suppresses a postsynaptic PN activity and its responsiveness to the transmitter glutamate for a long-term [3]. Subsequent in vitro studies demonstrated that the excitatory synaptic potential or current in a PN caused by $\mathrm{PF}$ activation is depressed by coupled stimulation of PFs and a CF $[4,5]$. This plasticity at PF-PN synapses is known as cerebellar long-term depression (LTD).

Ito and colleagues suggested involvement of LTD as an essential cellular mechanism in adaptation of vestibulo-ocular reflex (VOR), a model paradigm of motor learning [6]. Lisberger and colleagues opposed this view suggesting an important contribution of plasticity in vestibular nuclei to VOR adaptation [7]. On the other hand, Thompson and colleagues suggested that LTD is involved in a type of classical conditioning of eye-blink response [8]. A large number of subsequent studies have addressed the relation between LTD and motor learning [9-11]. Many studies have supported involvement of 
LTD in motor learning. However, there are also reports suggesting that motor learning can occur without LTD $[12,13]$. Thus, consensus has not been reached about roles of LTD in motor learning. Since discovery of LTD, various forms of synaptic plasticity at not only PF-PN synapses but also other synapses in the cerebellar cortex have been reported (Figure 1). Contribution of multiple types of cerebellar synaptic plasticity to motor learning has been proposed [11, 14-16]. In this mini-review, I will briefly discuss roles of LTD and other types of cerebellar plasticity in motor learning.

\section{LTD-deficient animals with motor learning failure}

Relation between LTD and motor learning has been studied extensively in two model paradigms, adaptation of VOR and classical conditioning of eye-blink response. Adaptation of another type of reflex eye movement, optokinetic response (OKR) has also been studied. VOR is a type of reflex to stabilize the visual image during head motion. Vestibular organs detect head motion, and drive eye balls to turn in the opposite direction of head motion so that the visual image becomes stable [17]. Adaptation of VOR occurs when an eyeball motion fails to stabilize the visual image on a retina. For example, when an animal is rotated together with rotation of the surrounding in the opposite direction, the visual image on a retina moves even if VOR occurs. In this situation eye movement needs to be increased to stabilize the visual image. Indeed, such a change of VOR is induced by continuous application of coupled rotation of an animal and the surrounding. Both gain-increase and 
gain-decrease adaptation of VOR occur. On the other hand, OKR is a visually-guided eyeball motion, and also works to stabilize the image on a retina during head motion. VOR is more efficient than OKR during fast head turn, and OKR is more efficient during slow turn.

In eye-blink conditioning an unconditioned eye-blinking is induced by applying air-puff or electrical stimulation around an eye, and coupling air puff or electrical stimulation with preceding conditioning stimulation such as sound presentation, results in occurrence of conditioned eye-blink response to the sound. Involvement of the cerebellum in these motor learning paradigms has been established.

Molecular and cellular studies on LTD revealed a number of molecules involved in LTD induction [9, 11]. Using such information, many types of mutant mice defective in LTD have been generated and their motor learning abilities such as adaptation of VOR or OKR, or eye-blink conditioning have been examined. Earlier studies on global knockout mice defective in LTD showed good correlation between LTD defects and motor learning failures [18]. Knockout mice of metabotropic glutamate receptor mGluR1, PN-specific ionotropic glutamate receptor-related molecule GluD2, a subtype of phospholipase PLC $\beta 4$, neuronal nitric oxide synthase nNOS, protein kinase $\mathrm{G}$ and $\mathrm{Ca}^{2+} /$ calmodulin-dependent kinase II $\alpha$ (CaMKII $\alpha$ ), showed defects in both LTD and motor learning [19-27], suggesting involvement of LTD in motor learning. Problems in interpretation of these results are that knockout of molecules in most of these mice was not cell-type specific, and that effects of knockout in PNs unrelated to LTD cannot be excluded. Another point I 
should note is that how LTD was induced and what types of motor learning paradigm were tested are different among these studies. Therefore, we should be cautious in interpretation of results.

In above mentioned molecules, GluD2 is selectively expressed in $\mathrm{PNs}_{\mathrm{s}}[18$, 20]. However, it has been revealed that GluD2 is involved in multiple functions such as formation and/or maintenance of PF-PN synapses, elimination of redundant CF input and presynaptic form of long-term potentiation (LTP) at PF-PN synapses [20, 28, 29]. Transgenic mice in which an inhibitor of protein kinase C is expressed only in PNs were generated [30]. They also show defects in both LTD and motor learning. However, potassium channel in PNs is also affected in the transgenic mice. More recently, an example of enhanced motor learning accompanied with facilitated LTD induction was reported. In delphilin knockout mice, LTD is more easily induced than in wild type mice, and that adaptation of OKR is facilitated [31]. Delphilin binds to GluD2 and relatively specifically expressed in PNs. Collectively, these studies have shown good correlations between LTD and motor learning ability, supporting involvement of LTD in motor learning, although the results only show correlations and are not conclusive.

\section{LTD-deficient animals with normal motor learning}

There are also papers reporting that normal motor learning occurs under LTD-suppressed conditions. Welsh et al., (2005) demonstrated that pharmacological prevention of LTD in rats does not affect eye-blink conditioning [12]. Schonewille et al., (2011) studied three types of mutant 
mice defective in LTD and found that all of them show normal adaptation of VOR, eye-blink conditioning and locomotion learning [13]. Mutant mice they examined were PICK1 knockout mice, knockin mice of the mutant ionotropic glutamate receptor subunit GluA2 devoid of the last $7 \mathrm{C}$-terminal amino acids, and another knockin mice of the GluA2 mutant in which single amino acid is replaced so that to inhibit phosphorylation of S880 of GluA2 by protein kinase $\mathrm{C}$. The mutation in the last mice seems very small and specific. All these 3 types of mutation seem to affect the final step of LTD expression, that is internalization of AMPA (a-amino-3-hydroxy-5-methyl-4-isoxazolepropionic acid)-type glutamate receptor. These studies indicate that normal motor learning can occur even if LTD is suppressed, and suggest that LTD is not essential for motor learning. However, they do not necessarily deny a possibility that LTD occurs and contributes to motor learning in wild type mice. Some other plasticity mechanisms might compensate suppressed LTD in the mutant mice. As described below, a type of LTP at inhibitory synapses on a PN might be able to compensate suppressed LTD. Further, there might be some subtle defects in motor learning ability in the LTD-defective mutant mice that could not have been detected. In any case, LTD is not a sole plastic mechanism contributing to motor learning, and other cerebellar synaptic plasticity mechanisms (Figure 1) seem to play roles in motor learning.

\section{Cerebellar cortical synaptic plasticity other than LTD}


At PF-PN synapses it is also known that post- and presynaptic LTP occur. Presynaptic LTP is induced by repetitive stimulation of PFs at a higher frequency $(4-8 \mathrm{~Hz})$ and postsynaptic LTP by that at a lower frequency $(1 \mathrm{~Hz})$ [4, 5, 32-35] (Figure 1). It has been suggested that a unidirectional synaptic plasticity might be saturated by training or experience, and might not be very effective in learning. Indeed, contribution of postsynaptic LTP at PF-PN synapses to motor learning has been suggested [36, 37].

Inhibitory synapses on a PN also undergo plasticity (Figure 1). CF activation or potent depolarization of a PN induces LTP of GABAergic synaptic transmission, which is called rebound potentiation (RP) [38, 39]. RP induction depends on the intracellular increase in $\mathrm{Ca}^{2+}$ concentration as LTD induction [40-42], and works to decrease the excitability of a PN as LTD. Molecular induction mechanism of RP has been extensively studied and clarified that several molecules such as CaMKII, protein phosphatases, and mGluR1 are involved in both RP and LTD [39, 41-47]. Similarities in induction conditions and molecular mechanisms, and also suppressive effects on the PN activity between RP and LTD, suggest that RP might work synergistically with LTD, and might compensate defects of LTD in certain conditions. As described above, LTD-deficient mutant mice in which signaling molecule such as mGluR1, nNOS, protein kinase $G$ or $\mathrm{Ca}^{2+} /$ calmodulin-dependent kinase II $\alpha$ is knocked out, show motor learning failures, whereas mutant mice in which the last selective step of LTD expression is affected do not show motor learning failure. It might be possible that in the former types of mutant mice RP is suppressed together 
with LTD and in the latter only LTD is abrogated, because some intracellular signaling molecules are involved in both LTD and RP. Thus, only coupled suppression of LTD and RP might have clearly affected motor learning.

Recently, RP-deficient transgenic mice were generated by expressing a peptide blocking interaction of $\mathrm{GABA}_{A}$ receptor and GABARAP $\left(\mathrm{GABA}_{A}\right.$ receptor associated protein) only in $\mathrm{PNs}_{\mathrm{s}}$ [48]. It was previously reported that the above protein interaction is necessary for expression and maintenance of $\mathrm{RP}$ [46]. The transgenic mice show defects in VOR adaptation, suggesting involvement of RP in motor learning [48]. However, the mutant mice showed normal OKR adaptation. At these inhibitory synapses on a PN other types of short-lasting plasticity have also been reported [49-52].

Synapses between PFs and a molecular layer inhibitory interneuron also undergo bidirectional plasticity $[53,54]$ (Figure 1). At these synapses coupled activation of a CF and PFs induces LTP, whereas stimulation of only PFs induces LTD. Directions of the above inhibitory synaptic plasticity are opposite to those at excitatory PF-PN synapses. Thus, they could synergistically work with LTD and LTP at excitatory PF-PN synapses $[11,15$, 16]. Further, it was reported that activities of molecular layer inhibitory interneurons tend to change in the opposite direction to those of nearby $\mathrm{PNS}_{\mathrm{s}}$ after application of certain stimulations [55, 56]. Thus, inhibitory interneuron activities might enhance $\mathrm{PN}$ responses to $\mathrm{PF}$ input. In addition, LTD has been reported at CF-PN synapses, which could influence LTD at PF-PN synapses and RP [57]. Synaptic plasticity occurs also in the granular layer. At mossy fiber-granule neuron synapses bidirectional plasticity occurs, 
which seems to contribute to fine tuning and redistribution of input information to the molecular layer $[58,59]$.

In addition to synaptic plasticity, plasticity of intrinsic dendritic excitability of a PN was reported [60]. Local depolarization of PN dendrite suppresses small-conductance $\mathrm{Ca}^{2+-}$ activated $\mathrm{K}^{+}$channel there, resulting in enhancement of excitatory synaptic response in a PN. This mechanism could contribute regulation of $\mathrm{PN}$ activity. Neuronal activity dependent plasticity of intrinsic excitability has been also reported in granule neurons and in cerebellar nuclear neurons [61, 62].

\section{Roles of cortex and nuclei}

We do not know how long LTD is maintained in vivo. In vitro studies reported that the PF-PN LTD chemically induced in a culture preparation lasts for 1-2 days [63]. On the other hand, there are studies suggesting that motor memory is transferred from the cortex to the cerebellar or vestibular nuclei a few days after the training [64]. In the cerebellar nuclei mossy fiber-nuclear neuron synapses show LTP depending on the inhibitory GABAergic input from PNs [65], whereas in the vestibular nuclei different synaptic plasticity is induced depending on the postsynaptic membrane potential [66, 67]. Such PN activity-dependent nuclear synaptic plasticity might contribute to the memory transfer from the cortex to nuclei for long-term storage of memory after LTD establishment in the cortex.

Raymond's group reported occurrence of VOR adaptation independent of $\mathrm{CF}$ input, and that optogenetic modulation of PN activity during vestibular 
stimulation changes VOR dynamics [68, 69]. These results suggest that there is motor learning process independent of CF activity, and that plasticity in the vestibular nuclei depending on the PN activity may play a critical role in VOR adaptation. On the other hand, Wada et al., (2008) reported that eye-blink conditioning training under suppression of $\mathrm{PF}-\mathrm{PN}$ synaptic transmission does not induce the conditioned response, but that the conditioned response appears after the recovery of transmission [70]. More recently, they also found that OKR adaptation does not occur under suppression of PF-PN synaptic transmission, but that the gain of OKR immediately increases after recovery of the transmission [71]. Thus, some learning process might take place during trainings without PF output. Certain plasticity mechanisms might proceed in the cerebellar or vestibular nuclei under a PF-activity suppressed condition without apparent effect on behavioral responses, which might appear only after recovery of the $\mathrm{PF}$ activity. These studies highlight important contribution of plasticity in the cerebellar or vestibular nuclei to motor learning.

Several types of synaptic plasticity in the cerebellar and vestibular nuclei have been reported $[65,66,67]$. However, they are somewhat controversial, and characterization of plasticity in the nuclei seems to be on the way. In the nuclei different types of neurons and synapses are intermingled [67], and detailed information about synaptic plasticity at specific types of synapses are lacking. I also would like to note that numbers of neurons and synapses are much smaller in the nuclei than those in the cerebellar cortex. Thus, the capacity for memory storage in the nuclei might be limited. 
Very recently, Wang et al. (2014) reported that short-term OKR adaptation is accompanied with transient decrease in the number of AMPA-type glutamate receptors at PF-PN synapses, and that long-term OKR adaptation after 5 consecutive daily trainings is accompanied with decrease in the number of PF-PN synapses in the cortex [72]. As decrease in the number of either AMPA receptors or PF-PN synapses can depress the synaptic transmission, these morphological changes might correspond to functional PF-PN LTD, although it is unclear whether these changes are restricted to only synapses related to OKR adaptation or not. If decrease in the PF-PN number corresponds to a later phase of LTD or a motor memory engram, it can be maintained for more than 10 days [72, 73], suggesting that LTD in the cortex can store memory for weeks. Morphological correlates of cerebellar synaptic organization to motor learning are interesting questions to be studied further.

\section{Remaining questions and future directions}

Various plasticity mechanisms in the cerebellum seem to contribute to refined motor control and learning. However, how each plasticity mechanism works during motor learning and influences neuronal activity, and whether plasticity mechanisms work independently or in collaboration, are unclear. In addition some plasticity mechanisms such as in the nuclei have not been well defined. Answers to these questions are required. In addition, effects of synaptic plasticity on behavior are essential information to be demonstrated. Direct modulation of activity of specific types of neuron so that to mimic the 
learned pattern by an optogenetic method, would contribute to clarification of cerebellar neuronal mechanism controlling motor learning.

\section{Acknowledgements}

I thank Drs. K. Funabiki, T. Yamazaki, S. Kawaguchi, Y. Tagawa and H. Tanaka for their constructive comments on the manuscript and Ms. Y. Tanaka for preparation of a figure. 


\section{References}

1) Marr D. A theory of cerebellar cortex. J Physiol 1969; 202: 437-470.

2) Albus J. A theory of cerebellar function. Math Biosci 1971; 10: 25-61.

3) Ito M, Sakurai M, Tongroach P. Climbing fibre induced depression of both mossy fibre responsiveness and glutamate sensitivity of cerebellar Purkinje cells. J Physiol 1982; 324: 113-134.

4) Sakurai M. Synaptic modification of parallel fibre-Purkinje cell transmission in in vitro guinea-pig cerebellar slices. J Physiol 1987; 394: 463-480.

5) Hirano T. Depression and potentiation of the synaptic transmission between a granule cell and a Purkinje cell in rat cerebellar culture. Neurosci Lett 1990; 119: 141-144.

6) Ito M. Cerebellar control of the vestibulo-ocular reflex-around the flocculus hypothesis. Ann Rev Neurosci 1982; 5: 275-296.

7) du Lac S, Raymond JL, Sejnowski TJ, Lisberger SG. Learning and memory in the vestibulo-ocular reflex. Ann Rev Neurosci 1995; 18: 409-441.

8) Thompson RF. In search of memory traces. Ann Rev Psychol 2005; 56: $1-23$.

9) Ito M. Cerebellar long-term depression: characterization, signal transduction, and functional roles. Physiol Rev 2001; 81: 1143-1195.

10) Ito M. The Cerebellum: Brain for an Implicit Self. FT Press, New Jersey. 2011; pp. 1-285.

11) Hirano T. Long-term depression and other synaptic plasticity in the 
cerebellum. Proc Japan Acad B 2013; 89: 183-195.

12) Welsh JP, Yamaguchi H, Zeng XH, Kojo M, Nakada Y, Takagi A, Sugimori M, Llinás RR. Normal motor learning during pharmacological prevention of Purkinje cell long-term depression. Proc Natl Acad Sci USA 2005; 102: 17166-17171.

13) Schonewille M, Gao Z, Boele HJ, Veloz MF, Amerika WE, Simek AA, De Jeu MT, Steinberg JP, Takamiya K, Hoebeek FE, Linden DJ, Huganir RL, De Zeeuw CI. Reevaluating the role of LTD in cerebellar motor learning. Neuron 2011; 70: 43-50.

14) Hansel C, Linden DJ, D'Angelo E. Beyond parallel fiber LTD: the diversity of synaptic and non-synaptic plasticity in the cerebellum. Nat Neurosci 2001: 4; 467-475.

15) Dean P, Porrill J, Ekerot CF, Jörntell H. The cerebellar microcircuit as an adaptive filter: experimental and computational evidence. Nat Rev Neurosci 2010; 11; 30-43.

16) Gao Z, van Beugen BJ, De Zeeuw CI. Distributed synergistic plasticity and cerebellar learning. Nat Rev Neurosci. 2012; 13: 619-635.

17) Robinson DA. The use of control systems analysis in the neurophysiology of eye movements. Ann Rev Neurosci 1981; 4: 463-503.

18) Hirano T. Cerebellar regulation mechanisms learned from studies on GluR82. Mol Neurobiol 2006; 33: 1-16.

19) Aiba A, Kano M, Chen C, Stanton ME, Fox GD, Herrup K, Zwingman TA, Tonegawa S. Deficient cerebellar long-term depression and impaired motor learning in mGluR1 mutant mice. Cell 1994; 7: 377-388. 
20) Kashiwabuchi N, Ikeda K, Araki K, Hirano T, Shibuki K, Takayama C, Inoue Y, Kutsuwada T, Yagi T, Kang Y, Aizawa S, Mishina M. Disturbed motor coordination, Purkinje cell synapse formation and cerebellar long-term depression of mice defective in the $\delta 2$ subunit of the glutamate receptor channel. Cell 1995; 81: 245-252.

21) Kishimoto Y, Kawahara S, Suzuki M, Mori H, Mishina M, Kirino Y. Classical eyeblink conditioning in glutamate receptor subunit $\delta 2$ mutant mice is impaired in the delay paradigm but not in the trace paradigm. Eur J Neurosci 2001; 13: 1249-1253.

22) Katoh A, Yoshida T, Himeshima Y, Mishina M, Hirano T. Defective control and adaptation of reflex eye movements in mutant mice deficient in either the glutamate receptor $\delta 2$ subunit or Purkinje cells. Eur J Neurosci 2005; 21: 1315-1326.

23) Miyata M, Kim H, Hashimoto K, Lee T, Cho S, Jiang H, Wu Y, Jun K, Wu D, Kano M, Shin H. Deficient long-term synaptic depression in the rostral cerebellum correlated with impaired motor learning in phospholipase C $\beta 4$ mutant mice. Eur J Neurosci 2001; 13: 1945-1954.

24) Lev-Ram V, Nebyelul Z, Ellisman MH, Huang PL, Tsien RY. Absence of cerebellar long-term depression in mice lacking neuronal nitric oxide synthase. Learn Mem 1997; 4: 169-177.

25) Katoh A, Kitazawa H, Itohara S, Nagao S. Inhibition of nitric oxide synthesis and gene knockout of neuronal nitric oxide synthase impaired adaptation of mouse optokinetic response eye movements. Learn Mem $2000 ; 7: 220-226$. 
26) Feil R, Hartmann J, Luo C, Wolfsgruber W, Schilling K, Feil S, Barski JJ, Meyer M, Konnerth A, De Zeeuw CI, Hofmann F. Impairment of LTD and cerebellar learning by Purkinje cell-specific ablation of cGMP-dependent protein kinase I. J Cell Biol 2003; 163: 295-302.

27) Hansel C, de Jeu M, Belmeguenai A, Houtman SH, Buitendijk GH, Andreev D, De Zeeuw CI, Elgersma Y. $\alpha$ CaMKII is essential for cerebellar LTD and motor learning. Neuron 2006; 51: 835-843.

28) Kuroyanagi T, Yokoyama M, Hirano T. Postsynaptic glutamate receptor $\delta$ family contributes to presynaptic terminal differentiation and establishment of synaptic transmission. Proc Natl Acad Sci USA 2009; 106: $4912-4916$.

29) Yamashita M, Kawaguchi S, Hirano T. Contribution of postsynaptic GluD2 to presynaptic R-type $\mathrm{Ca}^{2+}$ channel function, glutamate release and long-term potentiation at parallel fiber to Purkinje cell synapses. Cerebellum 2013; 12: 657-666.

30) De Zeeuw CI, Hansel C, Bian F, Koekkoek SK, van Alphen AM, Linden DJ, Oberdick J. Expression of a protein kinase C inhibitor in Purkinje cells blocks cerebellar LTD and adaptation of the vestibulo-ocular reflex. Neuron 1998; 20: 495-508.

31) Takeuchi T, Ohtsuki G, Yoshida T, Fukaya M, Wainai T, Yamashita M, Yamazaki Y, Mori H, Sakimura K, Kawamoto S, Watanabe M, Hirano T, Mishina M. Enhancement of both long-term depression induction and optokinetic response adaptation in mice lacking delphilin. PLoS One 2008; 3, e2297: 1-11. 
32) Hirano T. Differential pre- and postsynaptic mechanisms for synaptic potentiation and depression between a granule cell and a Purkinje cell in rat cerebellar culture. Synapse 1991; 7: 321-323.

33) Salin P, Malenka R, Nicoll R. Cyclic AMP mediates a presynaptic form of LTP at cerebellar parallel fiber synapses. Neuron 1996; 16: 797-803.

34) Lev-Ram V, Wong S, Storm D, Tsien R. A new form of cerebellar long-term potentiation is postsynaptic and depends on nitric oxide but not cAMP. Proc Natl Acad Sci US A 2002; 99: 8389-8393.

35) Coesmans M, Weber J, De Zeeuw CI, Hansel C. Bidirectional parallel fiber plasticity in the cerebellum under climbing fiber control. Neuron 2004; 44: 691-700.

36) Schonewille M, Belmeguenai A, Koekkoek SK, Houtman SH, Boele HJ, van Beugen BJ, Gao Z, Badura A, Ohtsuki G, Amerika WE, Hosy E, Hoebeek FE, Elgersma Y, Hansel C, De Zeeuw, CI. Purkinje cell-specific knockout of the protein phosphatase PP2B impairs potentiation and cerebellar motor learning. Neuron. 2010; 67: 618-628.

37) Ly R, Bouvier G, Schonewille M, Arabo A, Rondi-Reig L, Léna C, Casado M, De Zeeuw CI, Feltz A. T-type channel blockade impairs long-term potentiation at the parallel fiber-Purkinje cell synapse and cerebellar learning. Proc Natl Acad Sci USA 2013; 110: 20302-20307.

38) Kano M, Rexhausen U, Dreessen J, Konnerth A. Synaptic excitation produces a long-lasting rebound potentiation of inhibitory synaptic signals in cerebellar Purkinje cells. Nature 1992; 356: 601-604.

39) Kawaguchi S, Hirano T. Suppression of inhibitory synaptic potentiation 
by presynaptic activity through postsynaptic $\mathrm{GABA}_{\mathrm{B}}$ receptors in a Purkinje neuron. Neuron 2000; 27: 339-347.

40) Tanaka K, Khiroug L, Santamaria F, Doi T, Ogasawara H, Ellis-Davies G, Kawato M, Augustine GJ. $\mathrm{Ca}^{2+}$ requirements for cerebellar long-term synaptic depression: role for a postsynaptic leaky integrator. Neuron $2007 ; 54: 787-800$.

41) Kitagawa Y, Hirano T, Kawaguchi S. Prediction and validation of a mechanism to control the threshold for inhibitory synaptic plasticity. Mol Systems Biol 2009; 5, 280: 1-16.

42) Kawaguchi S, Nagasaki N, Hirano T. Dynamic impact of temporal context of $\mathrm{Ca}^{2+}$ signals on inhibitory synaptic plasticity. Scientific Reports $2011 ; 1,143: 1-12$.

43) Kuroda S, Schweighofer N, Kawato M. Exploration of signal transduction pathways in cerebellar long-term depression by kinetic simulation. J Neurosci 2001; 21: 5693-5702.

44) Kawaguchi S, Hirano T. Signaling cascade regulating long-term potentiation of $\mathrm{GABA}_{\mathrm{A}}$ receptor responsiveness in cerebellar Purkinje neurons. J Neurosci 2002; 22: 3969-3976.

45) Kawaguchi S, Hirano T. Integrin $\alpha 3 \beta 1$ suppresses long-term potentiation at inhibitory synapses on the cerebellar Purkinje neuron. Mol Cell Neurosci 2006; 31: 416-426.

46) Kawaguchi S, Hirano T. Sustained GABARAP structural change underlies long-term potentiation at inhibitory synapses on a cerebellar Purkinje neuron. J Neurosci 2007; 27: 6788-6799. 
47) Sugiyama Y, Kawaguchi S, Hirano T. mGluR1-mediated facilitation of long-term potentiation at inhibitory synapses on a cerebellar Purkinje neuron. Eur J Neurosci 2008; 27: 884-896.

48) Tanaka S, Kawaguchi S, Shioi G, Hirano T. Long-term potentiation of inhibitory synaptic transmission onto cerebellar Purkinje neurons contributes to adaptation of vestibulo-ocular reflex. J Neurosci 2013; 33: 17209-17220.

49) Yoshida T, Hashimoto K, Zimmer A, Maejima T, Araishi K, Kano M. The cannabinoid $\mathrm{CB} 1$ receptor mediates retrograde signals for depolarization-induced suppression of inhibition in cerebellar Purkinje cells. J Neurosci 2002; 22: 1690-1697.

50) Duguid IC, Smart TG. Retrograde activation of presynaptic NMDA receptors enhances GABA release at cerebellar interneuron-Purkinje cell synapses. Nat Neurosci 2004; 7: 525-533.

51) Satoh H, Qu L, Suzuki H, Saitow, F. Depolarization-induced depression of inhibitory transmission in cerebellar Purkinje cells. Physiol Reports 2013; 1, e00061: 1-16.

52) Hirano T, Kawaguchi S. Regulation and functional roles of rebound potentiation at cerebellar stellate cell-Purkinje cell synapse. Front Cell Neurosci 2014; 8, 42: 1-8.

53) Jörntell H, Ekerot CF. Reciprocal bidirectional plasticity of parallel fiber receptive fields in cerebellar Purkinje cells and their afferent interneurons. Neuron 2002; 34: 797-806.

54) Jörntell H, Ekerot CF. Receptive field plasticity profoundly alters the 
cutaneous parallel fiber synaptic input to cerebellar interneurons in vivo. J Neurosci 2003; 23: 9620-9631.

55) Ekerot CF, Jörntell H. Parallel fibre receptive fields of Purkinje cells and interneurons are climbing fibre-specific. Eur J Neurosci 2001; 13, 1303-1310.

56) Barmack NH, Yakhnitsa V. Functions of interneurons in mouse cerebellum. J Neurosci 2008; 28, 114-1152.

57) Hansel C, Linden DJ. Long-term depression of the cerebellar climbing fiber-Purkinje neuron synapse. Neuron 2000; 26: 473-482.

58)D'Angelo E, Rossi P, Gall D, Prestori F, Nieus T, Maffei A, Sola E. Long-term potentiation of synaptic transmission at the mossy fiber-granule cell relay of cerebellum. Prog Brain Res 2005; 148: 69-80.

59) D’Angelo E, De Zeeuw CI. Timing and plasticity in the cerebellum: focus on the granular layer. Trends Neurosci 2008; 32, 30-40.

60) Ohtsuki G, Piochon C, Adelman JP, Hansel C. SK2 channel modulation contributes to compartment-specific dendritic plasticity in cerebellar Purkinje cells. Neuron 2012; 75, 108-120.

61) Armano S, Rossi P, Taglietti V, D’Angelo E. Long-term potentiation of intrinsic excitability at the mossy fiber-granule cell synapse of rat cerebellum. J Neurosci 2000; 20, 5208-5216.

62) Zhang W, Shin JH, Linden DJ. Persistent changes in the intrinsic excitability of rat deep cerebellar nuclear neurons induced by EPSP or IPSP bursts. J Physiol 2004; 561, 703-719.

63) Murashima M, Hirano T. Entire course and distinct phases of day-lasting depression of mEPSC amplitudes in cultured Purkinje 
neurons. J Neurosci 1999; 19, 7317-7325.

64) Okamoto T, Endo S, Shirao T, Nagao S. Role of cerebellar cortical protein synthesis in transfer of memory trace of cerebellum-dependent motor learning. J Neurosci 2011; 31: 8958-8966.

65) Pugh J, Raman I. Potentiation of mossy fiber EPSCs in the cerebellar nuclei by NMDA receptor activation followed by postinhibitory rebound current. Neuron 2006; 51: 113-123.

66) Menzies JRW, Porrill J, Dutia M, Dean P. Synaptic plasticity in medial vestibular nucleus neurons: comparison with computational requirements of VOR adaptation. PLoS One 2010; 5, e13182, 1-17.

67) McElvain LE, Bagnall MW, Sakatos A, du Lac S. Bidirectional plasticity gated by hyperpolarization controls the gain of postsynaptic firing responses at central vestibular nerve synapses. Neuron 2010; 68, 763-775.

68) Ke MC, Guo CC, Raymond JL. Elimination of climbing fiber instructive signals during motor learning. Nat Neurosci 2009; 1, 1171-1179.

69) Nguyen-Vu TDB, Kimpo RR, Rinaldi JM, Kohli A, Zeng H, Deisseroth K, Raymond JL. Cerebellar Purkinje cell activity drives motor learning. Nat Neurosci 2013; 16: 1734-1736.

70) Wada N, Kishimoto Y, Watanabe D, Kano M, Hirano T, Funabiki K, Nakanishi S. Conditioned eyeblink learning is formed and stored without cerebellar granule cell transmission. Proc Natl Acad Sci USA 2007; 104: 16690-16695.

71) Wada N, Funabiki K, Nakanishi S. Role of granule-cell transmission in 
memory trace of cerebellum-dependent optokinetic motor learning. Proc Natl Acad Sci USA 2014; 111: 5373-5378.

72) Wang W, Nakadate K, Masugi-Tokita M, Shutoh F, Aziz W, Tarusawa E, Lorincz A, Molnar E, Kesaf S, Li YQ, Fukazawa Y, Nagao S, Shigemoto R. Distinct cerebellar engrams in short-term and long-term motor learning. Proc Natl Acad Sci USA 2014; 111: E188-E187.

73) Aziz W, Wang W, Kesaf S, Mohamed AA, Fukazawa Y, Shigemoto R. Distinct kinetics of synaptic structural plasticity, memory formation, and memory deay in massed and spaced learning. Proc Natl Acad Sci USA 2014; 111: E194-E202. 
Legend

Figure 1

Cerebellar circuit and synaptic plasticity. MF, mossy fiber; GN, granule neuron; PF, parallel fiber; PN, Purkinje neuron; IN, molecular layer interneuron; CN, cerebellar nuclei; VN, vestibular nuclei; IO, inferior olive; CF, climbing fiber; LTD, long-term depression; LTP, long-term potentiation; $\mathrm{RP}$, rebound potentiation. 


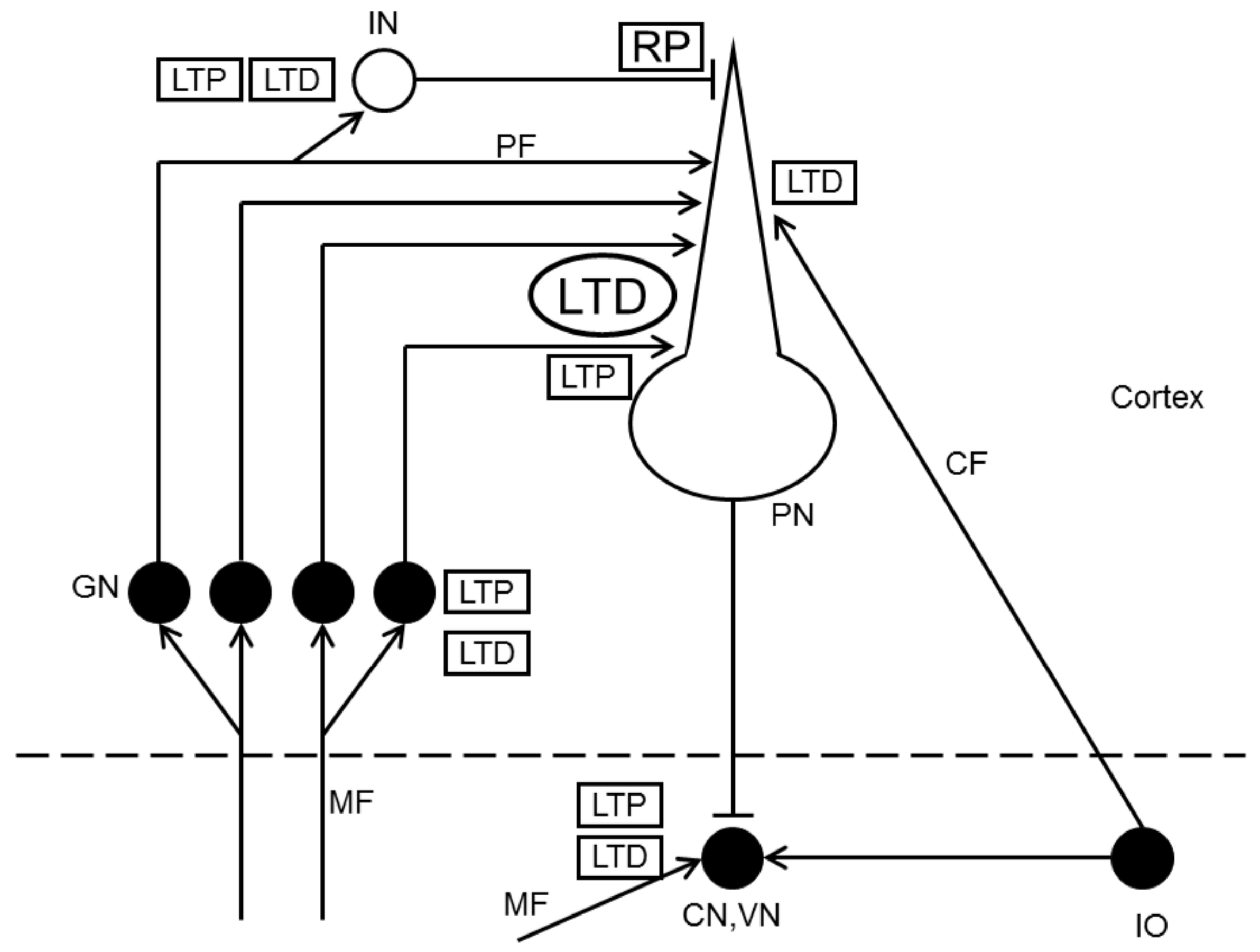

